\title{
GOLF PUTTIMG: EQUIVALENT PERFORMANCE WITH BALL FOCUSED AND TARGET FOCUSED AIMING
}

\author{
David Moffat, 1, A, B, C, D Howie J. Carson, 2, A, C, D Dave Collins 2, A, C, D \\ ${ }^{1}$ Myerscough College, Bilsborrow, Preston, UK \\ ${ }^{2}$ Institute for Coaching and Performance, University of Central Lancashire, Preston, UK

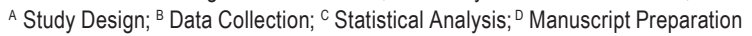 \\ Address for correspondence: \\ David Moffat \\ Myerscough College, \\ St Michael's Road, Bilsborrow, Preston, PR3 ORY, United Kingdom. \\ E-mail: dmoffat@myerscough.ac.uk
}

\begin{abstract}
Ahstract This study addressed several inconsistencies and omissions in golf putting research by testing the performance impact of target focused aiming. Participants were 22 high-level and experienced golfers, currently using ball focused aiming. Participants were allocated in a quasi-random fashion to ball or target focused aiming conditions and each performed 32 putts under competitive conditions on a natural putting green from a distance of $8 \mathrm{ft}$. Data were recorded as putts holed or missed and further categorised into putts missed long, short, left, right, short left, short right, long left and long right. There was no significant difference between conditions $(p>0.05)$ for any of the categories tested, despite participants' prior extreme familiarity and expressed preference for the ball focused technique. These results notwithstanding, we discuss possible explanations for target focused benefits, including the role of vision during putting, the impact of intention during execution and possible expectancy effects. While these findings hold potential implications for golf coaching, more research is clearly required to further understand causative mechanisms and to clarify the existence and nature of advantage for one technique over the other. Based on this study, we recommend that high-level and experienced golfers might try target focused aiming as a 'cost-free' experiment.
\end{abstract}

Key worlls high-level golfers, visual aiming, intention, coaching

\section{Introduction}

Technical skill creativity and innovation is an inevitable aspect of sport (Bar-Eli et al., 2006; Carson, Collins, 2011), most typically introduced by a few athletes and then, sometimes, adopted by many. Positive examples of innovation include Dick Fosbury's influence on the high jump and Jan Boklov's ski jumping technique. Both performers were first considered to have had unconventional styles. Recently, golf has experienced a similar challenge to known, accepted and comfortable orthodoxy regarding the closed and self-paced skill of putting. Specifically, while golfers have long kept their eyes fixed on the ball during the putting stroke, 'ball focused aiming' (hereafter termed BFA), several professionals (e.g., Major champions Jordan Speith and Louis Oosthuizen) have 
sometimes opted to direct their head, neck and eyes towards the target, 'target focused aiming' (hereafter termed TFA; Figure 1). For clarity, we define TFA as golfers fixing their gaze on the target (i.e., entry point of the hole for straight putts or the breaking point for sloped putts) prior to stroke initiation and throughout the execution. Notably, however, past golf research examining the position of the eyes have only considered BFA (e.g., Vickers, 1992; Vine, Moore, Wilson, 2011), meaning that eye gaze studies of TFA are under-researched and a topic of both practical and theoretical interest (Moffat, Collins, Carson, 2017).

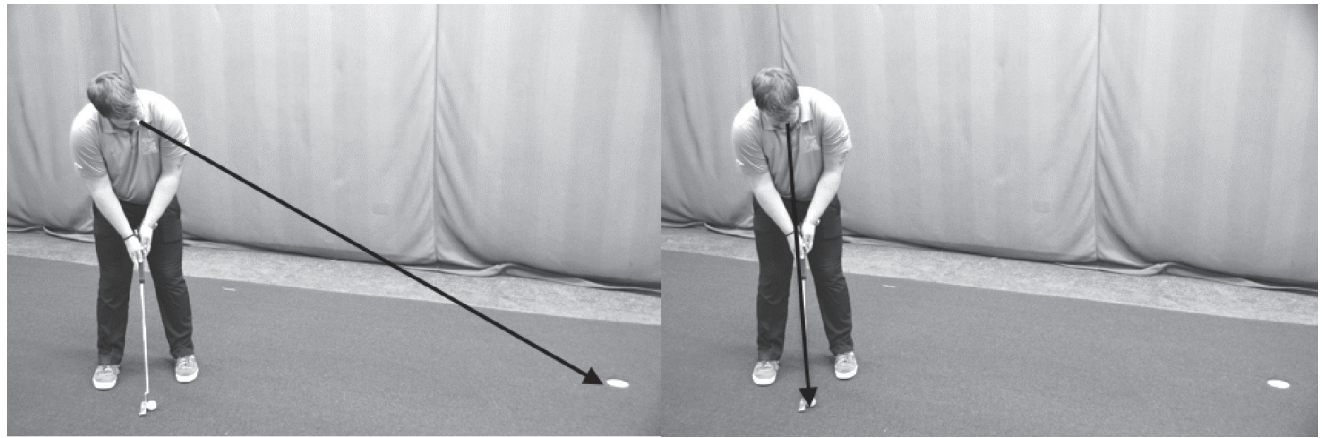

Figure 1. Golfer using TFA (left) and BFA (right) method

Regarding the underlying processes responsible for the performance and motor learning effects of TFA, several existing theories warrant consideration (e.g., Fischman, Christina, Vercruyssen, 1981; Shea, Morgan, 1979). However, for our present, mainly practical, purpose within a series of investigations currently underway, we will address this problem through Christina's (1987) basic and applied research framework. Christina distinguishes motor learning research across three levels (or motivations) of relevance for practical problem solving: Level 1, to "develop theory-based knowledge appropriate for understanding motor learning in general with no requirement to demonstrate its relevance for solving practical problems"; Level 2, to "develop theory-based knowledge appropriate for understanding the learning of practical skills in practical settings with no requirement to find immediate solutions to practical learning problems", and Level 3 , to "find immediate solutions to practical learning problems in practical settings with no requirement to develop theory-based knowledge at either Level 1 or Level 2" (p. 29). In other words, Level 1 research would typically explore general motor learning principles through sport, Level 2 research would seek to understand practices of sport and Level 3 research is designed to have a direct influence for sport (Collins, Kamin, 2012). Importantly, however, Christina explains that the interaction between Levels 1-3 should be such that basic theory not only informs practice, but practice must also inform theory. Accordingly, the empirical element of this paper is focused on Level 3 , in that this research examines the impact of TFA as a practical tool for reaching higher golf performance.

Currently, the evidence is equivocal as to whether TFA confers any performance advantage over BFA, especially for high-level golfers with an already well-established BFA style (Carson, Collins, 2016a). Importantly for coaching purposes, greater knowledge of whether it is advantageous, for whom, when and why, is necessary for its optimal application and before there can be a move towards an expertise-based approach to decision making 
(Collins, Burke, Martindale, Cruickshank, 2015). While it is beyond the scope of the present study to answer all these questions definitively, it aims to make some progress towards addressing this crucial need.

Providing the impetus for this recognised need, Moffat et al. (2017) recently conducted a review of TFA studies, over a period of 50 years (e.g., Bowen, 1968; MacKenzie, Foley, Adamczyk, 2011). In summary, their review found that it was currently impossible to evaluate TFA effectiveness due to several important inconsistencies and omissions across studies (see Moffat et al., 2017 Table 1 for a detailed account of study characteristics, pp. 37-41). For example, not all studies were conducted in representative golf environments or with golfers' own preferred equipment (e.g., putter). Furthermore, there was insufficient consideration of the meaningfulness of the task or relative engagement of participants as compared to a putting task under competitive conditions (cf. Christensen, Sutton, Mcllwain, 2016). Consider, for instance, the difference in motivations between an undergraduate student participating for module credits versus a genuine beginner golfer looking to improve their long-term skills and sport participation. More positively however, recent studies have been increasingly thorough in approach. For example, MacKenzie and MacInnis (2017) evaluated a far (TFA) versus near (BFA) target visual focus strategy with $6 \mathrm{ft}$., $10 \mathrm{ft}$. and $14 \mathrm{ft}$. breaking putts, among 28 experienced but high handicap golfers $\left(M_{\text {handicap }}=12.5\right)$. Results showed a significantly higher percentage of successful putts with TFA in comparison to BFA, especially for left-to-right breaking putts. Results indicated that TFA achieved a small but significantly higher percentage of successful putts $(40 \%)$ compared to BFA (37\%). This result was predominantly due to a $5 \%$ positive difference at $10 \mathrm{ft}$. ( $39 \%$ vs. $34 \%$ ), which could indicate a possible confounding variable of distance when evaluating TFA effectiveness. In an earlier study, MacKenzie et al. (2011), using 32 high handicap golfers ( $\left.M_{\text {handicap }}=18.7\right)$, examined process measures of putter head kinematics at $4 \mathrm{ft}$. and $13 \mathrm{ft}$. and determined that practice with TFA resulted in a significant reduction in putter speed variability compared to practice with BFA. However, TFA did not statistically affect the quality of impact, as assessed by variability in face angle, stroke path and impact spot at the precise moment the putter head contacted the ball. Crucially, nor did TFA improve performance at either of these distances when compared to a matched BFA group.

Perhaps unsurprisingly, as a result of inconsistency in past research findings, different researchers have drawn varying conclusions regarding TFA effectiveness. Alpenfels, Christina and Heath (2008), MacKenzie and Maclnnis (2017) and MacKenzie et al. (2011) all reported TFA benefits of kind (either process or outcome), whilst Gonzalez, Kegel, Ishikura and Lee (2012) reported a TFA disadvantage. Accordingly, Moffat et al. (2017) suggested that a coherent chain of investigation was required, with methodological features resolutely combined with improved control over variables as our understanding of TFA develops (cf. Goginsky, Collins, 1996). First and foremost, however, this research chain must begin with establishing whether TFA does, in fact, make a putting performance difference, when compared to BFA. Accordingly, this study addressed several past inconsistencies and omissions by testing TFA with BFA among high-level golfers in a naturalistic putting environment (on an actual golf green) while golfers used their own preferred putters and engaged in a meaningful putting competition. Specifically, we were interested in whether novel use of TFA among established BFA golfers would reveal any short-term difference in performance effectiveness.

Given the vast volume of practice completed by these participants on BFA, it was reasonable to assume that employing TFA for the first time would be associated with a performance decrement associated with the removal of vision on the ball. As previous literature suggests, visual information of the ball and putter enables the golfer to maintain precise alignment of the putter face at impact, which is necessary for successful performance (Nicklaus, 
Bowen, 2009; Pelz, Frank, 2000; Wannebo, Reeve, 1984). However, considering the inconsistency of results and methodological issues within the TFA literature mentioned already, we were interested to see if any advantage and/ or decrement did occur.

\section{Method}

\section{Participants}

Twenty-three high-level golfers of both professional (2 male, right-handed, $\mathrm{M}_{\text {age }}=34$ years, $S D=7$ ) and amateur (18 male, 15 right-handed and 1 left-handed, $M_{\text {age }}=19.4$ years, $S D=0.9, M_{\text {handicap }}=3.5, S D=2.3$ and 3 female, right-handed, $M_{\text {age }}=19$ years, $S D=1.6, M_{\text {handicap }}=5.3, S D=4.1$ ) status were recruited for this study. Amateur golfers were high-level, as reflected by their low handicap averages. However, one participant was removed (adjustment $n=22$ ) from the trials on his self-admission of having no interest in competing and committing to the task. Inclusion criteria required golfers to (a) be a current registered member of the Professional Golfers' Association of Great Britain and Ireland or be an amateur golfer with a current single figure handicap, (b) be available for four 20 min testing sessions, distributed before and after two competitive rounds of golf over a consecutive 2 day period, (c) have normal or corrected vision and (d) have no previous experience using TFA as determined by self-report. We obtained ethical approval from the university's ethics committee prior to conducting the study and all participants provided written informed consent prior to their participation.

\section{Procedure}

Two holes on the Victoria Golf Club practice putting green (Vilamoura; European Tour venue for the Portuguese Masters Championship) - identified for their challenging breaks and slopes - were selected as the venue for these putting trials. Green speed for both days was typical of championship conditions, registering 10 on the Stimpmeter for each day. ${ }^{1}$ Eight golf tee pegs were positioned around each hole, $8 \mathrm{ft}$. from the centre and equidistant to each other (Figure 2) providing a variety of challenging putts for participants (e.g., breaking right-to-left, uphill breaking, downhill breaking, straight putts and breaking left-to-right putts) and pushed just below the surface of the grass. These determined the points from which participants should putt and place his/her ball during the pre-putt routine.

Participants were assigned in a quasi-random fashion either to a BFA $(n=11)$ or TFA group $(n=11)$, with the groups balanced on professional/amateur status, handicap, handedness and gender. In an attempt to generate a meaningful putting competition, each participant was informed that prize money of $€ 100$ would be awarded to the golfer with the highest number of putts holed in each group, and we provided a competitive leaderboard that was promulgated to all participants over the 2 days of trials (Baumeister, 1984; Beilock, Carr, 2001; Guadagnoli, Bertram, 2014). Participants were instructed to follow their normal pre-putt routine and, in their own time, to attempt to hole as many putts as possible. Participants used their own putters and all putts were performed with new unmarked and legally conforming golf balls that we provided (Titleist Pro V1). The TFA group were provided with the instruction to follow their normal pre-putt routine and in their own time attempt to hole as many putts as possible whilst fixing their gaze on the target (e.g., entry point of the hole for straight putts or the breaking point for sloped putts) for

${ }^{1}$ Stimp is the measure of green speed and is determined by rolling a ball with an initial speed of $6 \mathrm{ft}$. $\mathrm{s}^{-1}$ from an elevated grooved track and measuring how far it rolls on a flat portion of the putting surface. 
a minimum period of $2 \mathrm{~s}$ prior to stroke initiation and to leave the eyes fixed on this position throughout the putting stroke (cf. Binsch, Oudejans, Bakker, Savelsbergh, 2009; Vickers, 2016). In contrast, the BFA group members were instructed to putt as they would naturally. To ensure compliance, observers made manipulation checks during each trial and through participant debriefs following each trial block to ensure that BFA and TFA instructional sets were followed.

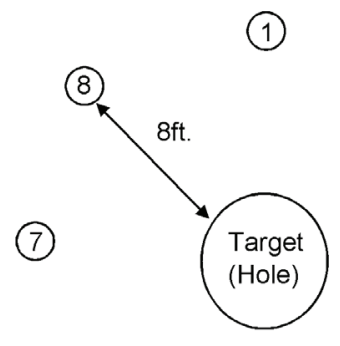

(6)
(2)

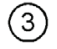

(4)

(5)

Figure 2. A schematic representation of the putting layout

The experiment was subdivided into four blocks of eight putts, resulting in a total of 32 putts over a 2 day period. Both groups completed their eight putts on two different holes for each day, progressing in either a clockwise or anticlockwise direction during the pre-round block, then in the alternate direction during the post-round block (see Figure 2). Importantly, pre-post round blocks, hole and direction were balanced between the two conditions. The putting distance ( $8 \mathrm{ft}$.) and location of each putt (eight different locations) were carefully selected (Karlsen, Smith, Nilsson, 2008). According to Pelz (1999), during competitive play $8 \mathrm{ft}$. represents a meaningful distance for a typical birdie putt, which is converted successfully approximately $50 \%$ of the time by tournament professional golfers (PGATour, 2017). Prior to commencement of the experimental putting trials, each participant was informed of the trial protocol, including the holes to be used and each of the eight marked locations around each hole. Participants were then provided with a 5 min familiarisation period in which they could putt from anywhere other than the selected trial holes using the BFA method only. The instruction for the TFA group to use BFA during the familiarisation period ensured the integrity of the novelty effect and negated any chance of raising performance during the trial. This process permitted participants to become accustomed to the characteristics of the green, such as speed, slopes, undulations and grain direction, which is a typical practice regimen for golfers prior to a competitive round. Inclusive of the familiarisation warm-up, the duration of each of the four blocks of trials ranged between 15-20 minutes per participant (Figure 3). 
Day 1

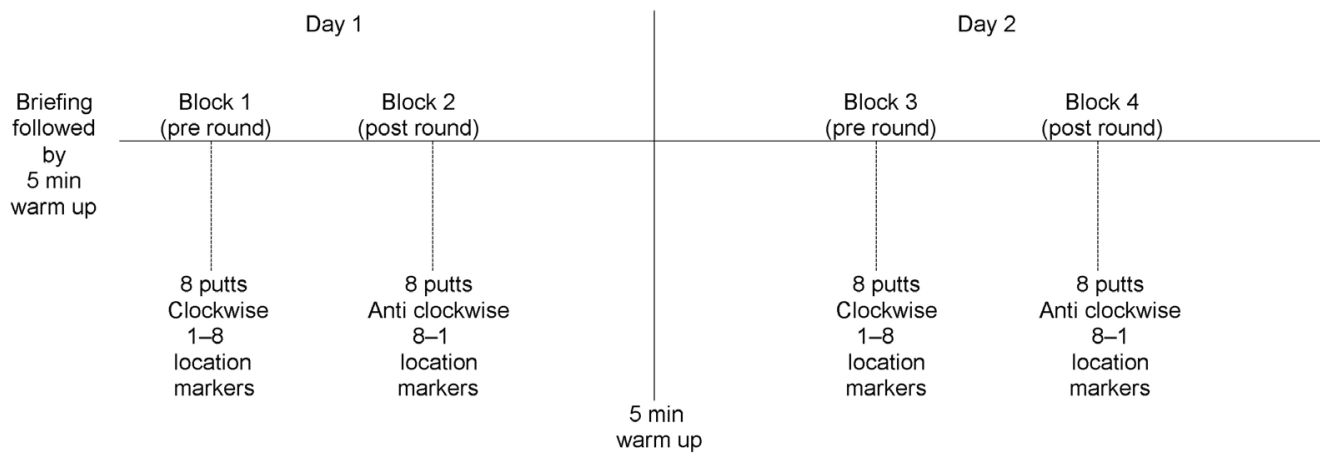

Figure 3. Experimental design

Following each putt, data were gathered using a customised score sheet. Results were first recorded as having been holed or missed, with missed putts further categorised based on a quadrant through the hole, creating four independent distance combined with direction outcomes.

\section{Data Analysis}

Data were analysed using SPSS Statistics 23.0 (IBM Corporation, New York, USA) software. We conducted independent samples $t$-tests on the following measures: the number of putts holed and for missed putts we assessed for misses short, long, right, left, short right, short left, long right and long left. The variable "short" was defined by the sum of scores for missed putts short left and short right. The variable "long" was defined by the sum of scores for putts missed long left and putts missed long right. The variable "left" was defined by the sum of scores for putts missed short left and putts missed long left. The variable "right" was defined by the sum of scores for putts missed short right and putts missed long right. Effect sizes were assessed using the Cohen's $(d)$ statistic and a $p$-value of less than 0.05 was considered as statistically significant.

\section{Results}

Descriptive statistics (means and standard deviations) for all measures are shown in Table 1. A consistent finding across all tests was that of a nonsignificant difference between TFA and BFA conditions. For outcome measures, results showed no significant difference between the mean putts holed, $t(20)=-0.33, p=0.74, d=-0.14$. There were also no significant differences when comparing putts missed short left, $t(20)=0.85, p=0.41, d=0.37$, long left, $t(20)=-0.26, p=0.80, d=-0.11$, short right, $t(20)=0.50, p=0.63, d=0.21$, long right, $t(20)=-0.07$, $p=0.95, d=-0.03$, left, $t(20)=0.00, p=1.00, d=0.00$, right, $t(20)=0.22, p=0.83, d=0.09$, long, $t(20)=-0.42$, $p=0.68, d=-0.18$ and short $t(20)=0.75, p=0.46, d=0.32$. Accordingly, these data determined that putts holed or putts missed were neither improved nor diminished by the imposition of the novel TFA approach among high-level golfers who preferred and were well established with the BFA approach. 
Table 1. Group comparisons of putting performance

\begin{tabular}{cccccccccc}
\hline Condition & Putts Holed & Short Left & Long Left & Short Right & Long Right & Miss Left & Miss Right & Miss Long & Miss Short \\
\hline TFA & $11.27 \pm 2.41$ & $0.82 \pm 1.17$ & $7.82 \pm 3.40$ & $2.00 \pm 2.83$ & $10.09 \pm 3.02$ & $8.64 \pm 3.14$ & $12.09 \pm 3.96$ & $17.91 \pm 3.05$ & $2.82 \pm 3.16$ \\
BFA & $11.64 \pm 2.73$ & $0.45 \pm 0.82$ & $8.18 \pm 3.19$ & $1.55 \pm 1.13$ & $10.18 \pm 3.12$ & $8.64 \pm 3.26$ & $11.73 \pm 3.69$ & $18.36 \pm 1.86$ & $2.00 \pm 1.79$ \\
\hline
\end{tabular}

\section{Discussion}

The purpose of this study was to address several inconsistencies and omissions within existing golf putting literature when testing the use of TFA compared to BFA with high-level golfers. In summary, and consistent with some previous findings pertaining to TFA performance effectiveness (e.g., Cockerill, 1978; MacKenzie et al., 2011), no significant difference between these putting techniques was found. In fact, to detect a significant difference $(p<0.05)$ for the number of putts holed, a post hoc analysis using Cohen's (1992) power primer calculation revealed the necessity for a sample size of 51,826 . While there is a substantial literature advising against the use of post hoc power analyses (e.g., Levine, Ensom, 2001), the simple point here is to demonstrate the low magnitude of impact which this more naturalistic manipulation exerted.

In view of this main finding, there are several interesting considerations that could be drawn. Firstly, it is possible that TFA does not necessarily benefit high-level golfers but helps to buffer against negative performances. One way in which this might be operationalised is to prevent distraction from putter head mechanics during the stroke. Another consideration is the extent to which TFA represented a sufficiently novel task when compared to already well established BFA control processes. In other words, the interaction between important putting processes involved in BFA and TFA were not different enough to cause any performance decrement. Finally, it may be that the visual change from BFA to TFA represents no challenge for high-level golfers. This would be surprising since some claim advantages from changing to TFA: nevertheless, this possibility must be considered. Whichever explanation is subsequently supported by further investigations, these nonsignificant research findings may be of considerable interest to golf practitioners and researchers.

\section{So why might some find TFA advantageous?}

It must be reiterated that, based on these data, no clear advantage or disadvantage for putting performance has emerged. However, as explained earlier, there are certainly some performers who endorse TFA as advantageous; a suggestion, which clearly merits ongoing investigation. Accordingly, in agreement with Christina's (1987) recommendation for promoting practice-informed theory, we now provide several theoretical reasons that could underpin the findings in high-level and experienced athletes. In turn, these explanations should serve to usefully inform future research to investigate TFA; thus, representing a reciprocal relationship between the different research levels.

Firstly, vision, or what golfers attend to, similar to advice to "keep your head still whilst putting" (see Lee, Ishikura, Kegel, Gonzalez, Passmore, 2008) may not be so important to performance once the green has been read and the stance adopted. Putting is notably different from other dynamic interceptive tasks where vision has been demonstrated to be an important factor (e.g., clay pigeon shooting; Causer, Bennett, Holmes, Jannelle, Williams, 
2010), because neither the ball nor target are in motion during the execution phase of this motor activity, making no ongoing visual activity (e.g., target tracking) needed. Compared to dynamic ball striking, the putting task is simpler (cf. Christensen et al., 2016) and more akin to target-oriented sports such as pistol shooting or archery. In this regard, there is evidence that closed and self-paced action skills progress from initially vision-dominant control to largely kinaesthetic-dominant control with learning, as shown by Bennett and Davids (1995) who found that skilled power lifters showed no performance decrement across execution conditions of full, ambient and no vision, whereas lesser skilled power lifters were hindered by these vision manipulations.

Secondly, and following from the previous point, the lack of effect from BFA and TFA technique manipulations may derive from the greater importance of some nonvisual factors to performance. Among possible nonvisual factors, is the role of psychomotor intention; referring to the activation of an internal motor skill representation through mental control (Schack, 2003). As an internal factor, intention reduces attention allocated toward external factors, such as visual stimuli (Jeannerod, 1994; Loze, Collins, Shaw, 1999; Shaw, 1996). Indeed, data derived from pre-shot EEG alpha power reactivity during elite air pistol shooting (Loze, Collins, Holmes, 2001; Loze et al., 1999), suggests that shots of greatest success occurred when not focussing on where the pistol was aimed; as indicated by reduced visual cortex activity. A similar focus on nonvisual activity may apply to putting with the TFA method. As Loze et al. (2001) explain, increased alpha power was associated with a state of internal focus as the elite shooter switched focus to the trigger pull following aiming completion (Wertheim, 1981). In other words, even though the eyes might be directed toward, even fixated on, an external target, visual processing was, in fact, decreased because shooters redirected their focus onto the execution process.

Thirdly, an explanation for these nonsignificant results that emanated from the debriefing sessions with golfers in the TFA group, is that golfers found the new TFA experience liberating in its tendency to redirect attention away from an over-focus on the ball to a new focus on the intended target. In effect, TFA may have screened against an over-focus on less important task-related cognitions by removing an over-focus on disruptive, external visual cues (Collins, Carson, Toner, 2016; Vickers, Williams, 2007) that may even lead to misdirected attention toward perceived inaccuracies in club head movement. In other words, TFA might be advantageous to high-level golfers not because it offers any additional benefits to performance per se, but because it limits the impact of detrimental factors. In the case of data presented in this study, the potential decrement in performance may have been countered by the removal of another challenge to putting under BFA conditions.

Finally, considering extensive work on expectancy effects within the psychology literature (e.g., Rosenthal \& Rubin, 1978), coaching practitioners and researchers must be cognisant of the potential for an interpersonal expectancy effect that may have enhanced TFA putting performance. While all these explanations seem reasonable, we favour the idea that improved internal intention may best explain why a novel putting approach did not contribute to a decrement in golfers' putting performance in this study. The importance of this internal mental representation derives from data and methodologies of Bertollo et al. (2016) and Loze et al. (2001) and from related closed skill research at the elite level. The simple principle underpinning these findings is that focusing on important, task-relevant technical skill elements can positively influence athletic performance (Carson, Collins, 2016a). This theorised explanation for some possible advantages to TFA (or at least from a demonstration of its neutrality with respect to performance decrements) should be further investigated in studies that manipulate nonvisual factors in putting performance, perhaps through studies of neural activations with varied attentional control strategies across the skill's entirety (Christensen et al., 2016; Eysenck, Derakshan, Santos, Calvo, 2007). 
While this study's strengths include the fact that the putting task was completed under more ecologically valid conditions, there were also important limitations. For example, evaluation of participant anxiety, through either psychometric or psychophysiological measures, to ensure equal levels of anxiety across TFA and BFA groups was not included (e.g., Chamberlain, Hale, 2007; Smith, Smoll, Cumming, Grossbard, 2006). Similarly, qualitative data on golfers' perceptions were not obtained (cf. MacPherson, Collins, Morriss, 2008). Also, this study only examined putting from $8 \mathrm{ft}$. and did not address any interactive effects at different putting distances when using TFA versus BFA. Of importance, a possible weakness in this study that warrants further consideration in future research, is that we studied only high-level golfers with prior BFA experience and do not know how prior experience with TFA might have affected these results. Our a priori expectation that golfers preferring, and familiar with only, BFA might have experienced a performance decrement by switching to a novel approach warrants further empirical analysis by comparing golfers with both prior BFA and prior TFA experience in a like study. Moreover, we appreciate that measuring performance with both final outcome (holed or missed putts) and with the use of combined distance and directional errors requires careful further consideration; it is an element of experimental design that has been poorly addressed within previous research analysing performance outcomes in target sports (see Fischman, 2015). Adding analyses of these variables to future study may provide greater insight to both theory and practice in sports skills development.

\section{Practical implications. For the moment}

It is worth noting that this is the first of several planned papers to explore the use of TFA. In this paper we have addressed some of the limitations of previous studies (e.g., high-level golfers using a real putting green with their own familiar equipment) and our data offer some interesting implications. For the moment it would be going beyond these data to make any concrete recommendations on, for instance, how coaches might use TFA with their clients, whether it is of benefit to yips effected golfers or the impact it may have on different skill levels of golfer. What is interesting is that, where previous work has recognised a distinct cost associated with the skill refinement process (Carson, Collins, 2016b), especially when not conducted in a careful and considered manner (cf. Carson, Collins, 2015; Toner, Carson, Collins, Nicholls, 2018), as an incomplete strategy TFA did not reveal any similar patterns of performance on first attempt. As such, for the sample tested here and from a distance of $8 \mathrm{ft}$., at least, we recommend that golfers might try TFA as a 'cost-free' experiment.

\section{Conclusion}

In conclusion, this study extends research into the use of TFA in golf putting and, in doing so, has responded to recent calls to address important omissions (Moffat et al., 2017). While there are still many more questions to be answered regarding this technique, data provide an informed stepping stone towards future investigations. Despite the general non-appeal of nonsignificant findings, it is important to understand why this is the case so that at the very least TFA does not become subject to misuse within the applied setting (Collins et al., 2015). Accordingly, this study has attempted to promote interaction between applied and basic research with the intention that each can inform the other (cf. Christina, 1987). For the moment, however, we await data that may illuminate the mechanism(s) involved during TFA. In light of recent perspectives on functional performance states and their psychological underpinnings (e.g., Bortoli, Bertollo, Hanin \& Robazza, 2012; Swann, Keegan, Crust, Piggott, 2016), it seems that performance psychology could prove an appropriate and beneficial lens through which to direct these efforts. Finally, it remains 
to be seen what would happen if high-level golfers committed to training with TFA for an extended period and what their perceptions are of the experience both during practice and competition.

\section{References}

Alpenfels, E., Christina, B., Heath, C. (2008). Instinct putting. New York: Penguin Group.

Bar-Eli, M., Lowengart, O., Barak, M.M., Oreg, S., Goldenberg, J., Epstein, S., Fosbury, R.D. (2006). Developing peak performers in sport: Optimization versus creativity. In: D. Hackfort, G. Tenenbaum (eds.), Essential processes for attaining peak performance (pp. 158-177). Oxford: Meyer \& Meyer Verlag.

Baumeister, R. F. (1984). Choking under pressure: Self consciousness and paradoxical effects of incentives on skifful performance. Journal of Personality and Social Psychology, 46, 610-620. DOI: 10.1037/0022-3514.46.3.610.

Beilock, S.L., Carr, T.H. (2001). On the fragility of skilled performance: What governs choking under pressure? Journal of Experimental Psychology: General, 130, 701-725. DOI: 10.1037/0096-3445.130.4.701.

Bennett, S., Davids, K. (1995). The manipulation of vision during the powerlift squat: Exploring the boundaries of the specificity of learning hypothesis. Research Quarterly for Exercise and Sport, 66, 210-218. DOI: 10.1080/02701367.1995.10608835.

Bertollo, M., di Fronso, S., Filho, E., Conforto, S., Schmid, M., Bortoli, L., Comani, S., Robazza, C.

(2016). Proficient brain for optimal performance: The MAP model perspective. PeerJ, 4, e2082. DOI: 10.7717/peerj.2082.

Binsch, O., Oudejans, R.R.D., Bakker, F.C., Savelsbergh, G.J.P. (2009). Unwanted effects in aiming actions: The relationship between gaze behavior and performance in a golf putting task. Psychology of Sport and Exercise, 10, 628-635. DOI: 10.1016/j. psychsport.2009.05.005.

Bortoli, L., Bertollo, M., Hanin, Y., Robazza, C. (2012). Striving for excellence: A multi-action plan intervention model for shooters. Psychology of Sport and Exercise, 13, 693-701. DOI: 10.1016/j.psychsport.2012.04.006.

Bowen, R.T. (1968). Putting errors of beginning golfers using different points of aim. Research Quarterly. American Association for Health, Physical Education and Recreation, 39, 31-35. DOI: 10.1080/10671188.1968.10616526.

Carson, H.J., Collins, D. (2011). Refining and regaining skills in fixation/diversification stage performers: The Five-A Model. International Review of Sport and Exercise Psychology, 4, 146-167. DOI: 10.1080/1750984x.2011.613682.

Carson, H.J., Collins, D. (2015). Tracking technical refinement in elite performers: The good, the better, and the ugly. International Journal of Golf Science, 4, 67-87. DOI: 10.1123/ijgs.2015-0003.

Carson, H.J., Collins, D. (2016a). The fourth dimension: A motoric perspective on the anxiety - performance relationship. International Review of Sport and Exercise Psychology, 9, 1-21. DOI: 10.1080/1750984X.2015.1072231.

Carson, H.J., Collins, D. (2016b). Implementing the Five-A Model of technical change: Key roles for the sport psychologist. Journal of Applied Sport Psychology, 28, 392-409. DOI: 10.1080/10413200.2016.1162224.

Causer, J., Bennett, S.J., Holmes, P.S., Jannelle, C.M., Williams, A.M. (2010). Quiet eye duration and gun motion in elite shotgun shooting. Medicine and Science in Sports and Exercise, 42, 1599-1608. DOI: 10.1249/MSS.0b013e3181d1b059.

Chamberlain, S.T., Hale, B.D. (2007). Competitive state anxiety and self-confidence: Intensity and direction as relative predictors of performance on a golf putting task. Anxiety, Stress, \& Coping, 20, 197-207. DOI: 10.1080/10615800701288572.

Christensen, W., Sutton, J., Mcllwain, D. (2016). Cognition in skilled action: Meshed control and the varieties of skill experience. Mind and Language, 31, 37-66. DOI: 10.1111/mila.12094.

Christina, R.W. (1987). Motor learning: Future lines of research. In: M.J. Safrit, H.M. Eckert (eds.), The cutting edge in physical education and exercise science research (pp. 26-41). Champaign, IL: Human Kinetics.

Cockerill, I.M. (1978). Visual control in golf putting. In: C.H. Nadeau, W.R. Halliwell, K.M. Newell, G.C. Roberts (eds.), Psychology of motor behaviour and sport (pp. 377-384). Champaign, IL: Human Kinetics.

Cohen, J. (1992). A power primer. Quantitative Methods in Psychology, 112, 155-159. DOI: 10.1037/0033-2909.112.1.155.

Collins, D., Burke, V., Martindale, A., Cruickshank, A. (2015). The illusion of competency versus the desirability of expertise: seeking a common standard for support professions in sport. Sports medicine (Auckland, N.Z.), 45, 1-7. DOI: 10.1007/s40279-014-0251-1.

Collins, D., Carson, H.J., Toner, J. (2016). Letter to the editor concerning the article "Performance of gymnastics skill benefits from an external focus of attention" by Abdollahipour, Wulf, Psotta \& Nieto (2015). Journal of Sports Sciences, 34, 1288-1292. DOI: 10.1080/02640414.2015.1098782. 
Collins, D., Kamin, S. (2012). The performance coach. In: S.M. Murphy (ed.), The Oxford handbook of sport and performance psychology (pp. 692-706). New York: Oxford University Press.

Eysenck, M.W., Derakshan, N., Santos, R., Calvo, M.G. (2007). Anxiety and cognitive performance: Attentional control theory. Emotion, 7, 336-353. DOI: 10.1037/1528-3542.7.2.336.

Fischman, M.G. (2015). On the continuing problem of inappropriate learning measures: Comment on Wulf et al. (2014) and Wulf et al. (2015). Human Movement Science, 42, 225-231. DOI: 10.1016/j.humov.2015.05.011.

Fischman, M.G., Christina, R.W., Vercruyssen, M.J. (1981). Retention and transfer of motor skills: A review for the practitioner. Quest, 33, 181-194. DOI: 10.1080/00336297.1981.10483753.

Goginsky, A.M., Collins, D. (1996). Research design and mental practice. Journal of Sports Sciences, 14, 381-392. DOI: $10.1080 / 02640419608727725$.

Gonzalez, D.A., Kegel, S., Ishikura, T., Lee, T. (2012). Effects of vision on head-putter coordination in golf. Motor Control, 16, 371-385. DOI: $10.1123 / \mathrm{mcj} \cdot 16.3 .371$

Guadagnoli, M.A., Bertram, C.P. (2014). Optimizing practice for performance under pressure. International Journal of Golf Science, 3 , 119-127. DOI: 10.1123/ijgs.2014-0021.

Jeannerod, M. (1994). The representing brain: Neural correlates of motor intention and imagery. Behavioral and Brain Sciences, 17 , 187-202. DOI: $10.1017 /$ S0140525X00034026.

Karlsen, J., Smith, G., Nilsson, J. (2008). The stroke has only a minor influence on direction consistency in golf putting among elite players. Journal of Sports Sciences, 26, 243-250. DOI: 10.1080/02640410701530902.

Lee, T.D., Ishikura, T., Kegel, S., Gonzalez, D., Passmore, S. (2008). Head-putter coordination patterns in expert and less skilled golfers. Journal of Motor Behavior, 40, 267-272. DOI: 10.3200/JMBR.40.4.267-272.

Levine, M., Ensom, M.H.H. (2001). Post hoc power analysis: An idea whose time has passed? Pharmacotherapy, 21, 405-409. DOI: 10.1592/phco.21.5.405.34503.

Loze, G.M., Collins, D., Holmes, P.S. (2001). Pre-shot EEG alpha-power reactivity during expert air-pistol shooting: A comparison of best and worst shots. Journal of Sports Sciences, 19, 727-733. DOI: 10.1080/02640410152475856.

Loze, G.M., Collins, D., Shaw, J.C. (1999). EEG alpha rhythm, intention and oculomotor control. International Journal of Psychophysiology, 33, 163-167. DOI: 10.1016/S0167-8760(99)00024-0.

MacKenzie, S.J., Foley, S M., Adamczyk, A.P. (2011). Visually focusing on the far versus the near target during the putting stroke. Journal of Sports Sciences, 29, 1243-1251. DOI: 10.1080/02640414.2011.591418.

MacKenzie, S.J., MacInnis, N.R. (2017). Evaluation of near versus far target visual focus strategies with breaking putts. International Journal of Golf Science, 6, 56-67. DOI: 10.1123/ijgs.2017-0009.

MacPherson, A.C., Collins, D., Morriss, C. (2008). Is what you think what you get? Optimizing mental focus for technical performance. The Sport Psychologist, 22, 288-303. DOI: 10.1123/tsp.22.3.288.

Moffat, D., Collins, D., Carson, H.J. (2017). Target versus ball focused aiming when golf putting: What has been done and what has been missed. International Journal of Golf Science, 6, 35-55. DOI: 10.1123/ijgs.2017-0002.

Nicklaus, J., Bowen, K. (2009). Jack Nicklaus: Putting my way. New Jersey: John Wiley \& Sons.

Pelz, D. (1999). Dave Pelz's short game bible. London: Aurum Press.

Pelz, D., Frank, J.A. (2000). Dave Pelz's putting bible: The complete guide to mastering the green. New York: Doubleday.

PGATour (2017). Statistics: TOTAL 1 PUTTS - 5-10'. Retrieved from: http://www.pgatour.com/stats/stat.421.html.

Rosenthal, R., Rubin, D.B. (1978). Interpersonal expectancy effects: The first 345 studies. Behavioral and Brain Sciences, 1, $377-386$. DOI: $10.1017 /$ S0140525X00075506.

Schack, T. (2003). The relationship between motor representation and biomechanical parameters in complex movements: Towards an integrative perspective of movement science. European Journal of Sport Science, 3, 1-13. DOI: 10.1080/17461390300073201.

Shaw, J.C. (1996). Intention as a component of the alpha-rhythm response to mental activity. International Journal of Psychophysiology, 24, 7-23. DOI: 10.1016/S0167-8760(96)00052-9.

Shea, J.B., Morgan, R.L. (1979). Contextual interference effects on the acquisition, retention, and transfer of a motor skill. Journal of Experimental Psychology: Human Learning and Memory, 5, 179-187. DOI: 10.1037/0278-7393.5.2.179.

Smith, R.E., Smoll, F.L., Cumming, S.P., Grossbard, J.R. (2006). Measurement of multidimensional sport performance anxiety in children and adults: The Sport Anxiety Scale-2. Journal of Sport and Exercise Psychology, 28, 479-501. DOI: 10.1123/jsep.28.4.479. 
Swann, C., Keegan, R., Crust, L., Piggott, D. (2016). Psychological states underlying excellent performance in professional golfers: "Letting it happen" vs. "making it happen". Psychology of Sport and Exercise, 23, 101-113. DOI: 10.1016/j.psychsport.2015.10.008.

Toner, J., Carson, H.J., Collins, D., Nicholls, A.R. (2018). The prevalence and influence of psychosocial factors on technical refinement amongst highly-skilled tennis players. International Journal of Sport \& Exercise Psychology, Advance online publication. DOI: 10.1080/1612197X.2018.1511621.

Vickers, J.N. (1992). Gaze control in putting. Perception, 21, 117-132

Vickers, J.N. (2016). Origins and current issues in Quiet Eye research. Current Issues in Sport Science, 1, 101. DOI: 10.15203/ CISS_2016.101.

Vickers, J.N., Williams, A.M. (2007). Performing under pressure: The effects of physiological arousal, cognitive anxiety, and gaze control in biathlon. Journal of Motor Behavior, 39, 381-394. DOI: 10.3200/JMBR.39.5.381-394.

Vine, S.J., Moore, L.J., Wilson, M.R. (2011). Quiet eye training facilitates competitive putting performance in elite golfers. Frontiers in Psychology, 2. DOI: 10.3389/fpsyg.2011.00008.

Wannebo, M., Reeve, T.G. (1984). Effects of skill level and sensory information on golf putting. Perceptual and Motor Skills, 58, 611613. DOI: 10.2466/pms.1984.58.2.611.

Wertheim, A.H. (1981). Occipital alpha activity as a measure of retinal involvement in oculomotor control. Psychophysiology, 18, 432439. DOI: 10.1111/j.1469-8986.1981.tb02476.x.

Cite this article as: Moffat, D., Carson, H.J., Collins, D. (2018). Golf Putting: Equivalent Performance with Ball Focused and Target Focused Aiming. Central European Journal of Sport Sciences and Medicine, 3 (23), 5-16. DOI: 10.18276/cej.2018.3-01. 